Original article

\title{
Distracted driving: Direct observation of mobile phone use among motorised two-wheeler drivers in the rapidly motorising city of Hyderabad, India
}

\author{
A.P. Sandya ${ }^{\text {a }}$, Lakshmi Archana $\mathrm{Y}^{\mathrm{b}}$, Melissa Glenda Lewis ${ }^{\mathrm{c}}$, Tetali Shailaja ${ }^{\mathrm{c},}$ \\ ${ }^{\text {a }}$ Karuna Trust, India \\ ${ }^{\mathrm{b}}$ Action in Distress, India \\ ${ }^{\mathrm{c}}$ Indian Institute of Public Health Hyderabad, Telangana State, India
}

\section{A R T I C L E I N F O}

\section{Keywords:}

Road traffic injury

Distracted driving

Mobile phone use

Motorised two-wheelers

Hyderabad

India

\begin{abstract}
A B S T R A C T
Introduction: Mobile phone use in India is increasing exponentially, accompanied by rapid motorization. We estimated the factors influencing mobile phone use among motorised two-wheeler (MTW) drivers in the rapidly motorizing city of Hyderabad, India.

Methods: Using a proforma observation checklist, 15-min observations were conducted. The vehicle flow was video recorded during the entire duration for confirmation. Poisson regression (robust variance) was used to calculate prevalence ratios (PR) and $95 \%$ CI for the association between mobile phone use and various factors (the type of road, time of day, and week).

Results: Mobile phone use among 11787 MTW drivers observed was 16.49\% (95\% CI 15.83\%-17.17\%), a majority in 'hands-free' mode. It was higher on weekends than weekdays (adjusted PR $=1.44,95 \%$ CI 1.30 to 1.59); on Non-busy roads than Busy roads (PR $=1.43,95 \%$ CI 1.29 to 1.58 ) and on Non-Peak hour than Peak-hour (PR $=1.29$, 95\% C I 1.16 to 1.43 ) after adjusting for other factors.

Conclusions: Type of road, day, and time were significant factors affecting mobile phone use among MTW in Hyderabad, it being almost one and half times higher on non-busy roads, non-peak time, and during weekends. These findings are especially important in a rapidly motorizing urban context. Penalties for both hand-held and hands-free mobile phone use must be included in the newly amended Motor Vehicle Act of India, with strict, consistent, and visible enforcement.
\end{abstract}

\section{Introduction}

Mobile phone use is increasing tremendously in India, with an estimated. 1.18 billion users. ${ }^{1}$ With the automobile industry growing at $10 \%$ annually, India is also motorizing rapidly. ${ }^{2}$ Driving while using the mobile phone is a dangerous combination.

Mobile phone use while driving is a major distraction and a risk factor for road traffic injuries (RTI). When drivers are distracted, their attention is temporarily divided between driving and other activities not related to driving. Distraction-auditory, cognitive, visual, or biomechanical-is hazardous. The risk of death is estimated to be four times higher for a driver using a phone while driving. ${ }^{3}$

Two-wheeler drivers using mobile phones is an additional risk factor.
According to the Ministry of Road Transport and Highways, about 0.46 million crashes claimed about 0.15 million lives in 2017 in India, and two-wheelers accounted for $33 \%$ of all road crashes. ${ }^{4}$

An observational study conducted in Mysore in 2014 estimated 1.14 mobile phone users for every 100 vehicles, not just MTW. ${ }^{5}$ A multi-city study in India with 1749 respondents reported that $47 \%$ of all drivers studied received calls while driving. ${ }^{6}$ Others studies reported that nearly $60 \%$ of Indian two-wheeler users 'instinctively' answered their mobile phones when driving. ${ }^{7}$ In India, the share of RTI due to mobile phones is estimated to be $1.8 \%$, (versus $70 \%$ due to speeding). ${ }^{4}$ Although the traffic conditions of the two countries are not comparable, the estimate from Great Britain was similar, where distraction was cited as contributing to $2 \%$ of road crashes. ${ }^{3}$ Both figures are likely under estimates,

\footnotetext{
* Corresponding author. Indian Institute of Public Health Hyderabad, Plot \# 1, A.N.V.Arcade, Amar Co-op Society, Kavuri Hills, Madhapur, Hyderabad, 500033, Telangana State, India.

E-mail addresses: sandya.97sri@gmail.com (A.P. Sandya), archu.yarasani@gmail.com (L. Archana Y), melissa.g@iiphh.org (M. Glenda Lewis), shailaja.t@iiphh. org (T. Shailaja).
} 
perhaps due to subjective judgement of police.

Taking cognisance of this growing threat, the India Motor Vehicle Act (MVA) penalises drivers using mobile phones. A recent amendment to the Act (September 2019) is worrisome to motorists, owing to the stiffer penalties proposed. ${ }^{8}$ Under section 184 of the MV Act, "whoever drives a motor vehicle in a manner 'dangerous to the public' is liable to a fine of up to INR 5,000, (USD 70) with imprisonment of 6-12 months" (compared to the previous fine of INR 1000 and/or 0-6 months in jail, which was almost never implemented). The use of hand-held communication devices while driving is on the list of 'dangerous driving' but 'hands-free' mode is ignored.

There are few peer-reviewed epidemiological studies on mobile phone use among MTW drivers in rapidly motorizing Indian cities. Hyderabad, where this study was conducted, is a rapidly urbanising city ${ }^{9}$ with an estimated 8 million MTW. ${ }^{10}$ We aimed to estimate the percentage of hands-free and hand-held mobile phone use among MTW drivers in Hyderabad.

\section{Methods}

Study design and setting

Cross-sectional study was conducted at different locations (Madhapur, Ameerpet, and Medchal Highway) in Hyderabad, representing the IT corridor, business area, and industrial areas, respectively.

Participants

Motorised two-wheeler (MTW) drivers.

Sample size

The primary outcome was the percentage of mobile phone use among MTW drivers. Using sample size for estimation of single proportion with a relative precision of $10 \%$, proportion of mobile phone use among MTW drivers as 0.20 , and $5 \%$ level of significance, a minimum sample of 1539 was estimated.

\section{Sampling technique}

All MTW drivers in the mentioned time frame (15 min) were included.

\section{Observation checklist}

An observation checklist was specifically developed for this study with fields on time, day, place, number of vehicles, and mobile phone users, including hand-held and hands-free mode (Earphones with cord and Bluetooth, or mobile phone partially tucked inside the helmet).

\section{Data collection}

15-min observations were conducted on each road (busy and nonbusy) for seven days (weekday and weekend) at different times (peak and non-peak hours). Each of the observations was conducted under various road circumstances on multiple days and times. The working definitions were (i) 'Weekday': Monday to Thursday and 'Weekend': Friday to Sunday (ii) 'Peak hour': 6 p.m.-11 p.m. and 'Non-peak hour': 11 p.m. to 6 a.m. (iii) 'Busy road': main roads/national/state highway and 'Non-busy road': street/side roads.

Observations were conducted by two research assistants with survey experience and training. One researcher was assigned to manually assess total vehicular flow as the vehicles passed through a fixed point near the signal. A mechanical counter was used for this. Another researcher was assigned to fill the observation checklist, at the same time and spot. Vehicles only on one side of the median (unidirectional flow) were observed. The vehicle flow was video recorded during the entire duration for confirmation.

\section{Statistical analysis}

Data from the observation checklist was entered in STATA 14 and analysed. Frequency with percentage was presented for categorical factors. Poisson regression (robust variance) was used to study the factors affecting mobile phone use. Independent variables included for the analyses were time (Peak and Non-Peak hour), day (Weekend and Weekday), and type of road (Busy and Non-busy road). The outcome considered was mobile phone use (yes/no). Univariate analysis was conducted for the identified factors independently with the outcome. An unadjusted prevalence ratio (PR) with a $95 \%$ Confidence Interval (CI) was reported. All three factors were included in the model and $\mathrm{P}$ value $\leq$ 0.05 was considered statistically significant. Adjusted PR with 95\% CI was then reported. Number (1) was indicated as a reference category. The overall performance of the model was measured by two chi-square tests, Pearson, and deviance statistic.

\section{Ethics approval}

The Ethics Committee of the Indian Institute of Public Health Hyderabad had waived off the requirement for approval since this was only a traffic observation study.

\section{Results}

A total of 11,787 MTV drivers were observed at busy (Maitrivanam, Road number 36, Medchal Highway) and non-busy roads (Ayyappa Society, Road number 44 and Road number 45), during the peak and non-peak hours for $15 \mathrm{~min}$ on all days/week. Observations were conducted and recorded (9345 on weekday and 7293 on weekend); (4005 during peak hour and 7782 during non-peak hour); (2442 on busy road and 9345 on non-busy road).

The percentage of mobile phone use was $16.49 \%$ (95\% CI: $15.83-17.17)$. Majority of use $71.76 \%$ (95\% CI: 69.70-73.75) was in the hands-free mode- Earphones/Bluetooth/Phone inside the helmet [Table 1].

The percentage of mobile phone use was significantly higher (64.51\%) on Weekends compared to Weekdays (35.49\%) ( $\mathrm{P}=0.009)$. Similarly, use was higher (73.92\%) on Non-busy roads than Busy roads $(26.08 \%)(\mathrm{P}<0.001)$ and higher during Non-Peak hour $(69.91 \%)$ than Peak-hour $(30.09 \%)(\mathrm{P}<0.001)$. The results of univariate and multiple Poisson regression are shown in Table 2.

The percentage of mobile phone use was almost one and half times higher on Weekends than Weekdays (Adjusted PR $=1.44,95 \% \mathrm{CI}$ : 1.30-1.59) and during Non-Peak hour than Peak-hour (Adjusted PR = 1.29, 95\% CI: 1.16-1.43). Likewise, the percentage of mobile phone use was more on Non-busy than Busy roads (Adjusted PR $=1.43$, 95\% CI: 1.29-1.58) [Table 2].

Table 1

Percentage of mobile phone use among MTW drivers in Hyderabad.

\begin{tabular}{llll}
\hline Mobile phone use & $\%(95 \% \mathrm{CI})$ & Type of users $(\mathrm{n})$ & $\%(95 \% \mathrm{CI})$ \\
\hline Users $(\mathrm{n}=1944)$ & $16.49 \%(15.83$, & Hands-free $(\mathrm{n}=$ & $71.76 \%(69.70$, \\
& $17.17)$ & $1395)$ & $73.75)$ \\
& & Hand-held $(\mathrm{n}=$ & $28.24 \%(26.25$, \\
& & $549)$ & $30.30)$ \\
& & Total $(\mathrm{N}=1944)$ & $100 \%$ \\
Non-Users ( $=$ & $83.50 \%(82.83$, & - & - \\
$9843)$ & $84.17)$ & - & - \\
Total $(\mathrm{N}=$ & $100 \%$ & & \\
$11,787)$ & & & \\
\hline
\end{tabular}


Table 2

Factors affecting mobile phone use among MTW drivers in Hyderabad.

\begin{tabular}{|c|c|c|c|c|c|c|c|}
\hline \multirow[b]{2}{*}{ Factors } & \multirow[b]{2}{*}{ Categories } & \multicolumn{2}{|l|}{ Mobile phone use } & \multicolumn{2}{|l|}{ Univariate } & \multicolumn{2}{|l|}{ Multiple } \\
\hline & & Yes $(n=1944)$ & No $(n=9843)$ & Unadjusted PR (95\% CI) & $P$ value & Adjusted PR (95\% CI) & $P$ value \\
\hline \multirow[t]{2}{*}{ Day } & Weekday & $690(35.49 \%)$ & $3804(38.65 \%)$ & 1 & 0.009 & 1 & $<0.001 *$ \\
\hline & Weekend & $1254(64.51 \%)$ & $6039(61.35 \%)$ & $1.12(1.02,1.23)$ & & $1.44(1.30,1.59)$ & \\
\hline \multirow[t]{2}{*}{ Time } & Peak hour & $585(30.09 \%)$ & $3420(34.75 \%)$ & 1 & $<0.001^{*}$ & 1 & $<0.001^{*}$ \\
\hline & Non-Peak hour & $1359(69.91 \%)$ & $6423(65.25 \%)$ & $1.20(1.09,1.32)$ & & $1.29(1.16,1.43)$ & \\
\hline \multirow[t]{2}{*}{ Type of road } & Busy road & $507(26.08 \%)$ & $1935(19.66 \%)$ & 1 & $<0.001^{*}$ & 1 & $<0.001^{*}$ \\
\hline & Non-busy & 1437 (73.92\%) & 7908 (80.34\%) & $1.35(1.22,1.49)$ & & $1.43(1.29,1.58)$ & \\
\hline
\end{tabular}

\section{Discussion}

The percentage of mobile phone use among MTW drivers in various locations in Hyderabad was 16.49 (95\% CI: 15.83-17.17). Most common use was the 'hands-free' mode. Type of road, day, and time were significant factors affecting mobile phone use, it being almost one and half times higher on non-busy roads, non-peak time, and during weekends.

We could not identify the purpose of hands-free mode, and it could have been for listening to music. If the MTW driver had head/earphones or blue-tooth, it was assumed to be 'hands-free'. We were not able to categorize mobile use based on those who were only listening, only talking or only texting. We were unable to distinguish between active mobile usage, mentally distracted talking, and both mentally and visually distracted texting. The limited observation of $15 \mathrm{~min} /$ location could have led to misclassification due to measurement errors. We did not check the inter-rater reliability of the observations, although we validated the observations via random checks of the video recordings. We observed the two wheelers who had stopped at traffic junctions for a red light. We are confident that the observers were accurate in their counts because MTW drivers in India mount their mobile phone in the line of sight, on their vehicles, and this was easily visible to the data collectors, along with the earphone cords. We could therefore see and note active usage of mobile phones. Despite the limitations, we used direct observation of 11,787 MTV drivers, lending strength to the study, versus selfreported mobile phone use, which could be under-reported by participants to give socially acceptable answers, as was shown with other road safety risk factor studies. ${ }^{11}$

Our study focussed on MTW drivers, as they are vulnerable road users. ${ }^{4,12}$ MTW are also the main mode of transport for the ubiquitous food and other delivery services, with their attendant risk of RTI. A recent study in Chennai showed that $45.6 \%$ of food delivery personnel reported driving while using their mobile phones, and $28.3 \%$ reported sustaining a RTI. ${ }^{13}$ The prevalence of mobile phone use in our study was higher than that reported in studies from Vietnam ${ }^{14}: 8.66 \%$ (95\% CI: 8.30-9.01\%), and in 3 Mexican cities ${ }^{15}$ (0.64\% with 95\% CI: 0.42-0.92), perhaps due to the variations in the local prevailing traffic conditions in different countries. Overall, studies have found up to $11 \%$ mobile use, with the use in hands-free mode likely to be higher. Evidence suggests that this behaviour is increasing rapidly as a result of the exponential growth in the use of mobile phones generally in society. The WHO report also mentions that in many countries, the extent of this problem remains unknown. ${ }^{3}$

This study shows that mobile phone use was significantly higher during weekends, non-peak hours, and on non-busy roads. This could be due to lower enforcement and associated 'low perceived risk' of getting caught and should be further investigated using qualitative methods. Hyderabad has been consistently listed among 'top-ten for road crashes' in India, ${ }^{4}$ and laxity in enforcement will make it worse. Although the 15 min observations in this study may not be fair representation, this work is important because it can help guide enforcement frequency and timing. Further work is needed to see if the proportion of mobile us reported here is impacted by weather and traffic conditions in smaller Indian cities. Two wheelers go past fast, at times in herds and at times in parallel. Adjustments in analysis, sensitivity analysis, multi-collinearity etc could be considered in future studies to obtain more granular data.
Driver distraction is an important risk factor for RTI. Drivers using mobile phones are approximately four times more likely to be involved in a crash, suggesting the impact of cognitive distraction on driving behaviour and crash risk. Hands-free use seems to have a similar risk to hand-held mode. ${ }^{3}$ The new directive (Sept 2020) from the Ministry of Transport specifies that drivers can use hand held mobile devices only for navigation, by fixing the phone on the vehicle dashboard such that it shall not disturb the concentration of the driver while driver. However, although the new MTV Act in India stipulates a stiff penalty for dangerous driving that includes mobile phone use, it largely ignores 'hands-free' mode.

\section{Conclusion}

This study was the first to examine mobile use among motorised twowheeler drivers in Hyderabad, India, using direct-observation method. Almost a fifth of the people observed used mobile phones while driving, adding to their already 'vulnerable road user' tag. These findings are especially important in a rapidly motorizing urban context, with its accompanying exponential increase in mobile phones. Strong legislation panning hand-held and hands-free mode are crucial. Strict, consistent, and visible enforcement must be combined with public awareness campaigns highlighting the risk of mobile phone use and accompanying penalties.

\section{Funding}

There was no funding received for this study.

\section{Author contribution}

SAP and LA collected, analysed and interpreted the data. MGL guided the conduct of the study, analysed the data, and contributed to revising the manuscript. ST conceptualised and designed the study, interpreted the data, and drafted the manuscript. All authors read and approved the final manuscript.

\section{Research checklist}

This manuscript has been prepared using the Strobe guidelines for reporting the results of cross sectional studies.

What is already known on the subject?

- Mobile phone use while driving is a major distraction and a risk factor for road traffic injuries.

- There are an estimated 1.18 billion mobile phone users in India.

- Driving while using mobile phone is a dangerous combination.

What does this study add?

- Mobile phone use among motorised two-wheeler drivers in various locations in Hyderabad was $16.5 \%$

- The type of road and day and time were significant factors affecting mobile phone use. 


\section{Declaration of competing interest}

None declared.

\section{References}

1 Telecom regulatory authority of India. https://main.trai.gov.in/sites/default/files PR No.22of2019.pdf; 2019.

2 Indian automobile industry analysis. https://www.ibef.org/industry/automobiles -presentation; 2018.

3 Mobile Phone Use: A Growing Problem of Driver Distraction. Geneva, Switzerland: World Health Organization; 2011.

4 Road Accidents in India. Ministry of Road Transport and Highways. Government of India; 2017.

5 Majgi SMAA. Epidemiology of handheld cell phone use while driving: a study from a South Indian city. Int J Prev Med. 2018;9(29).

6 https://www.autocarpro.in/news-national/india-distracted-driving-study-reveals-adverse -impact-mobile-phones-road-safety.

7 Save life foundation. http://savelifefoundation.org/wp-content/uploads/2017/04/Distr acted-Driving-in-India_A-Study-on-Mobile-Phone-Use-Pattern-and-Behaviour.pdf-; 2017.
8 Gazette of India, Ministry of Law and Justice. The motor vehicles (amendment) act, 2019NO. 32 OF 2019. http://egazette.nic.in/WriteReadData/2019/210413.pdf.

9 World Population Review. http://worldpopulationreview.com/world-cities/hydera bad-population/.

10 Transport Department, Government of Telangana. http://transport.telangana.gov. in/html/statistics_vehicles.html.

11 Wadhwaniya S, Gupta S, Mitra S, et al. A comparison of observed and self-reported helmet use and associated factors among motorcyclists in Hyderabad city, India. Publ Health. 2019;144(S):62-69.

12 Global Status Report on Road Safety. Geneva: World Health Organization; 2018.

13 Vijayasankari A, et al. Prevalence of road traffic accident among food delivery workers in southern Chennai. IOSR J Nurs Health Sci. 2020;9(3):17-20.

14 Truong LT, Nguyen HT, De Gruyter C. Mobile phone use among motorcyclists and electric bike riders: a case study of Hanoi, Vietnam. Jun Accid Anal Prev. 2016;91: 208-215. https://doi.org/10.1016/j.aap.2016.03.007. Epub 2016 Mar 22. PMID: 27015225.

15 Pérez-Núñez Ricardo, Hidalgo-Solórzano Elisa, Juan Daniel Vera-López, et al. The prevalence of mobile phone use among motorcyclists in three Mexican cities. Traffic Inj Prev. 2014;15(2):148-150. https://doi.org/10.1080/ 15389588.2013.802776. 